\title{
REFLEXÕES ACERCA DO TORCER A PARTIR DA PANDEMIA DO NOVO CORONAVÍRUS
}

Recebido em: 01/08/2020

Aprovado em: 15/11/2020

Licença:@) (1) @

\author{
Georgino Jorge de Souza Neto ${ }^{1}$ \\ Universidade Estadual de Montes Claros (UNIMONTES) \\ Montes Claros - MG - Brasil \\ Priscila Augusta Ferreira Campos ${ }^{2}$ \\ Universidade Federal de Ouro Preto (UFOP) \\ Ouro Preto - MG - Brasil \\ Silvio Ricardo da Silva ${ }^{3}$ \\ Universidade Federal de Minas Gerais (UFMG) \\ Belo Horizonte - MG - Brasil
}

RESUMO: Este artigo teve por objetivo investigar os movimentos produzidos no futebol, notadamente no torcer, condicionados pela ocorrência do Novo Coronavírus no Brasil. Para tanto, buscamos na primeira parte do texto um subsídio histórico, analisando os impactos da Gripe Espanhola de 1918 no futebol e no torcer à época, e os desdobramentos da constituição de uma identidade torcedora ao longo do século XX. Posteriormente, focamos nosso olhar para as mudanças ocorridas a partir da década de 1990, que altera profundamente os sentidos do esporte, em função de uma nova concepção de gerenciamento do espetáculo futebolístico, centrada na mercantilização de todo o processo, e consequentemente formatando novos modelos de torcida/torcedores. Por fim, alinhavamos reflexões deste contexto com a chegada da pandemia do COVID-19 no país, prospectando possíveis reordenamentos no cenário do futebol e do torcer.

PALAVRAS-CHAVE: Futebol. Torcer. Pandemias.

\section{REFLECTIONS ON SUPPORTER FROM THE NEW CORONAVIRUS PANDEMIC}

ABSTRACT: This article aimed to investigate the movements produced in football, notably in cheering, conditioned by the occurrence of the New Coronavirus in Brazil. For this purpose, we sought in the first part of the text a historical subsidy, analyzing the impacts of the Spanish Flu of 1918 on football and cheering at the time, and the

\footnotetext{
${ }^{1}$ Docente do Departamento de Educação e Desporto, Universidade Estadual de Montes Claros, Doutor. Pesquisador do Observatório do Futebol e do Torcer/Unimontes.

${ }^{2}$ Docente da Escola de Educação Física, Universidade Federal de Ouro Preto. Doutora. Pesquisadora do Grupo de Estudos sobre Futebol e Torcidas - GEFuT-UFMG

${ }^{3}$ Docente da Universidade Federal de Minas Gerais e do Programa de Pós-Graduação Interdisciplinar em Estudos do Lazer. Coordenador do Grupo de Estudos sobre Futebol e Torcidas - GEFuT-UFMG
} 
consequences of the constitution of a supporter identity throughout the 20th century. Subsequently, we focused our attention on the changes that occurred since the 1990s, which profoundly changes the meanings of the sport, due to a new conception of management of the football spectacle, centered on the commercialization of the whole process, and consequently formatting new models of crowd / fans. Finally, we aligned reflections of this context with the arrival of the COVID-19 pandemic in the country, prospecting possible reorganizations in the soccer and cheering scene.

KEYWORDS: Soccer. Supporter. Pandemics.

\section{Introdução}

Torcer por um clube de futebol, acompanhar diariamente as notícias sobre ele e o time, ir torcer nos estádios, assistir aos jogos na televisão, ouvir os jogos pelo rádio, se fazer presente nas suas respectivas mídias sociais, comprar produtos que fazem alusão a tal agremiação, estão, entre outras, como opções de lazer de milhões de pessoas em todo o mundo. Mais evidente em alguns países do que em outros, porém, é difícil saber de algum lugar do planeta que esteja completamente alheio a tal fenômeno.

Contudo, assim como em todas as esferas da vida, a atual pandemia do Covid-19 afetou de maneira avassaladora essa experiência de torcer por um clube de futebol. No Brasil, as partidas foram suspensas em março ${ }^{4}$ e reiniciaram em julho ${ }^{5}$, revelando uma novidade em termos de período tão extenso sem futebol.

Além de certa preocupação com os riscos à saúde de todos e todas que trabalham para promoção, organização e desenvolvimento do espetáculo futebolístico, o retorno acontece sem a presença dos torcedores nos estádios (CBF, 2020), o que traz outra configuração ao esporte e ao torcer. Há prejuízos econômicos imensos, sobretudo para os clubes que não terão a renda da bilheteria. Para suprir esse déficit, buscam outras formas

\footnotetext{
${ }^{4}$ Disponível em: https://www.mg.superesportes.com.br/app/noticias/futebol/futebolnacional/2020/03/17/noticia_futebol_nacional,3841122/pandemia-do-novo-coronavirus-afeta-25-dos-27estaduais-no-brasil.shtml. Acesso: 10 ago. 2020.

${ }^{5}$ Disponível em: https://globoesporte.globo.com/futebol/noticia/quando-voltam-os-estaduais-veja-asituacao-de-cada-campeonato-pelo-brasil.ghtml. Acesso: 10 ago. 2020.
} 
de engajamento e vínculo com o torcedor, lançando planos de sócio-torcedores para a compra de ingressos virtuais para as partidas, vendendo o cotidiano do clube em suas redes sociais, evocando o consumo como parte constituinte do pertencimento clubístico.

Dessa forma, esse artigo tem por objetivo refletir acerca dos impactos no lazer a partir da pandemia do novo coronavírus (Covid-19), mais especificamente tratando dos impactos sobre a experiência do torcer no futebol brasileiro.

Para tal, inicialmente recuperaremos na história indícios acerca do torcer durante a outra grande pandemia que nos assombrou no início do século XX, no caso a Gripe Espanhola. Logo após faremos uma análise do quanto o modelo de gerenciamento e modernização implantado de maneira mais acintosa a partir dos anos 1990 impactou o torcer no Brasil. Por fim, diante das já sentidas e presumíveis consequências da pandemia Covid-19 para o lazer da população brasileira, as reflexões advindas desse trabalho poderão subsidiar as políticas públicas e privadas que regem o futebol brasileiro que impactam diretamente no torcer.

\section{Primeiros Movimentos do Torcer e a Gripe Espanhola de 1918}

Ao longo de um século e meio de história, a experiência social do futebol não pode ser pensada sem a presença da massa humana que confere sentido à sua existência: a torcida. O torcer é a marca de maior significação dentre os muitos elementos que circundam o universo futebolístico.

No entanto, os modos de torcer não permaneceram inalterados no tempo. É possível notarmos, embora algumas similaridades tenham se mantido, um redimensionamento na organização, nos comportamentos e nos valores dos torcedores e torcidas. Aspectos como classe social, violência, identidade, gênero, política, dentre outros, foram se reconfigurando historicamente no espaço de atuação do torcer e seus sujeitos. 
Ainda em seus primeiros movimentos, o futebol, percebido enquanto uma prática distintiva de uma ascendente burguesia, não organizava os seus interesses para além do jogo em si (e dos seus desdobramentos como uma vivência socialmente restrita da modernidade). Assim, o que entendemos hoje como "torcida" não se apresentava como tal no panorama constituído pelos agentes produtores do futebol entre o final do século XIX e início do XX. O comportamento aristocrata ditava o modelo das pessoas que assistiam ao espetáculo futebolístico (àquela época um espetáculo mais social que esportivo). A denominação de "assistência" explicava bem a ideia do público presente às arquibancadas, posto que o sentido estava mais voltado à integração de uma festa social reservada a um estrato bastante específico do que uma fervorosa vinculação a uma entidade esportiva. Nas palavras de José Miguel Wisnik,

[...] esse futebol torna-se logo a vitrine de um modo de vida europeizado, cosmopolita, e um índice de civilização e progresso, além de um traço de distinção social. Pondo-se como esporte vocacionado congenitamente para gente fina, seja na plateia ou no gramado, o futebol dos grandes clubes consolida-se como moda elegante ao longo já da primeira década do século (WISNIK, 2008, p. 200).

Mas logo este cenário sofreria as suas primeiras e importantes modificações. O caráter passional e arrebatador do futebol rapidamente produziria efeitos para além do seu círculo elitista, que controlava as esferas do jogo. Os indícios iniciais deste processo seriam percebidos na crescente popularização do esporte, fortemente atrelada à construção de uma marca identitária, com profundo arcabouço emocional.

Em Belo Horizonte, o quadro constitutivo do futebol e do torcer reflete as nuances indiciárias dessa paisagem maior guardadas as particularidades de uma cidade que flertava com o desejo de se tornar a sede de experiências da modernidade nas primeiras décadas do século XX, tornando o esporte cada vez mais protagonista neste intento. 
Um acontecimento em particular se tornaria um marco emblemático do futebol e especialmente do torcer na cidade: a realização do evento denominado "Taça Bueno Brandão" ${ }^{6}$. A realização deste campeonato iria gestar uma nova concepção de público assistente que, motivado pelas disputas acirradas dos clubes pelo título de campeão, começava a construir um sentimento de afeição pelos times. Embora ainda estivessem distantes de se comportarem como torcedores apaixonados, a assistência passava a nutrir uma admiração e uma preferência por um dos clubes, criando uma identificação entre o sujeito e a instituição esportiva.

As referências nominais dos indivíduos que assistiam aos jogos permaneciam as mesmas, mas passaram a ganhar a companhia de outros termos, como registrado na seguinte nota, relacionada a uma das partidas da "Taça Bueno Brandão":

Realiza-se hoje, no "ground" do Prado Mineiro, um "match" de "foot-ball", entre o "Athletico" e o "America". Tendo em vista as condições em que se acham estes valorosos adversarios, o "match" de hoje reveste-se de caracter decisivo para o campeonato aberto para a disputa da taça "Bueno Brandão", e, portanto, há de, sem duvida, levar ao Prado Mineiro uma extraordinariaaffluencia de admiradores $^{7}$ dos dois contendores (MINAS GERAES, 1914, p. 11).

O termo "admiradores" cunhava, naquele instante, uma nova possibilidade de frequentar os campos de futebol. Não se ia mais apenas para assistir, ou para compor um cenário social de distinção e pertencimento. Para além destas características, ia-se ao campo agora também para admirar um determinado time de futebol. Este comportamento inaugurava o que pretendemos denominar de "momento de transição entre a assistência e o torcer", onde a passagem de uma etapa para a outra começava a ser construída.

\footnotetext{
${ }^{6}$ Júlio Bueno Brandão governou por duas vezes o estado de Minas Gerais durante a República Velha $\left(1^{\circ}\right.$ mandato: 27/10/1908 a 03/04/1909 e $2^{\circ}$ mandato: 07/09/1910 a 07/09/1914). A associação de figuras políticas ao contexto futebolístico começaria a se configurar como uma prática recorrente e indicativo do uso da estrutura de poder e seus personagens, que também percebem neste movimento a possibilidade de ganho de capital político em seu favor.

${ }^{7}$ Grifo nosso.
} 
Outro importante indício encontra-se na aparição da palavra "torcida" nos periódicos. A primeira referência encontrada nos periódicos da capital mineira que utilizou este novo vocábulo para designar o público espectador dos jogos de futebol foi encontrada no jornal oficial do Estado, o Minas Geraes, em setembro de 1915. Ao anunciar o encontro entre os "teams" do Athletico e do Yale, o jornalista lança mão do termo torcida, no intuito de caracterizar os grupos de espectadores com predileção por uma das equipes disputantes. Assim descrevia o texto da nota:

O "field" do prado Mineiro, domingo, será, certamente, pequeno, para conter o numero consideravel dos que apreciam as boas partidas do "association". Batem-se os "teams" do Athletico e do "Yale", os dois mais fortes concorrentes do presente campeonato. Dadas as condições de "treno" em que se acham as "équipes" dos dois "clubs", impossivel será fazer-se um prognostico. Sera, pois, uma bella tarde, proporcionada aos amantes do violento "sport", pelo que, certamente, concorrerão as "torcidas" dos dois clubs, ao bello "ground" do Prado Mineiro (MINAS GERAES, 1915, p. 6).

É sempre salutar buscar uma relação teórica que pressuponha a palavra, ou ainda, os sentidos atribuídos às palavras. Não foi, por certo, o surgimento da palavra "torcida" que inaugurou as modificações de conduta da assistência. Mas não se pode ignorar que o aparecimento da mesma denotava uma prática, uma circunstância, singularmente distinta.

Poucos anos após o incremento de formação das torcidas (entendido como grupos de sujeitos vinculados identitariamente com uma agremiação futebolística, gerando o que compreendemos como o fenômeno nominado "pertencimento clubístico"), o mundo seria tomado pelo temor pandêmico da Gripe Espanhola, em 1918. E o futebol não passaria ileso a este acontecimento, por promover em seu derredor uma grande aglomeração de pessoas.

Com as medidas preventivas de distanciamento social sendo largamente recomendadas, as partidas de futebol foram profundamente impactadas. Os campeonatos são interrompidos e as cidades se vêem esvaziadas em seus domingos, já acostumadas com o movimento esportivo produzido pelo jogo bretão. 
Em todo o país, é possível notar, em maior ou menor escala, uma alteração do cotidiano ligado ao futebol. No Campeonato Carioca daquele ano, as partidas transcorreram normalmente até o dia 13 de outubro. A essa altura, no entanto, o avanço da gripe espanhola já afetava o futebol no estado, e essa foi a única partida disputada no mês, tendo sido retomado a disputa do certame apenas no dia 8 de dezembro. O campeão do certame carioca de 1918 foi o Fluminense, mas, no entanto o Tricolor das Laranjeiras sofreu com a epidemia. O jogador Archibald French faleceu durante a competição após ser infectado. Outro detalhe da campanha é que o Fluminense, com pontuação já para ser campeão, optou por não atuar na última rodada, temendo pelos riscos da Gripe Espanhola, perdendo de W.O para o Carioca. Em 1918 também estava previsto para o Rio de Janeiro sediar a Copa América, chamada de Campeonato Sul-Americano à época. No entanto, a Gripe Espanhola obrigou a organização a adiar a competição para o ano seguinte, conforme noticiado pelo Jornal do Brasil:

Figura 01: Notícia sobre a Gripe Espanhola e a Necessidade de Adiamento do Campeonato Sul Americano de Futebol. ${ }^{8}$

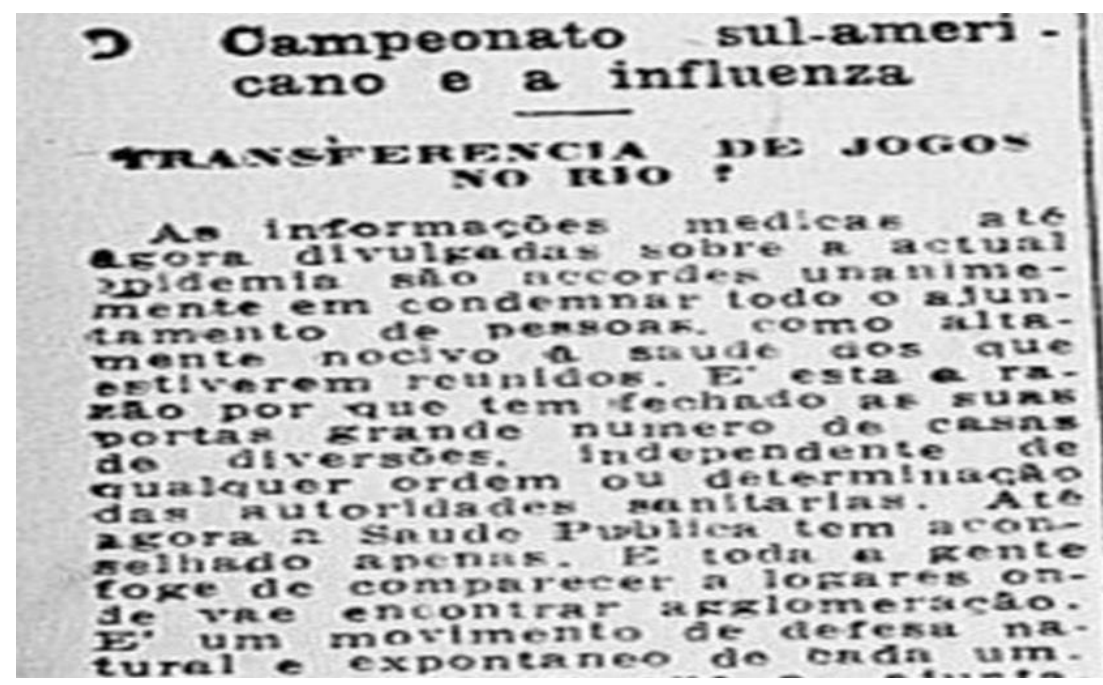

\footnotetext{
${ }^{8}$ Jornal do Brasil, 17 de outubro de 1918.
} 
O cartão postal alusivo ao Campeonato Sul Americano (Figura 02) explicita, em sua divulgação, o ano de 1918 como período de realização do evento esportivo (que só ocorreria de fato entre os dias 11 e 29 de maio do ano seguinte, em função da pandemia):

\section{Figura 02: Cartão Postal do Campeonato Sul Americano de Foot- Ball/1918. 9}

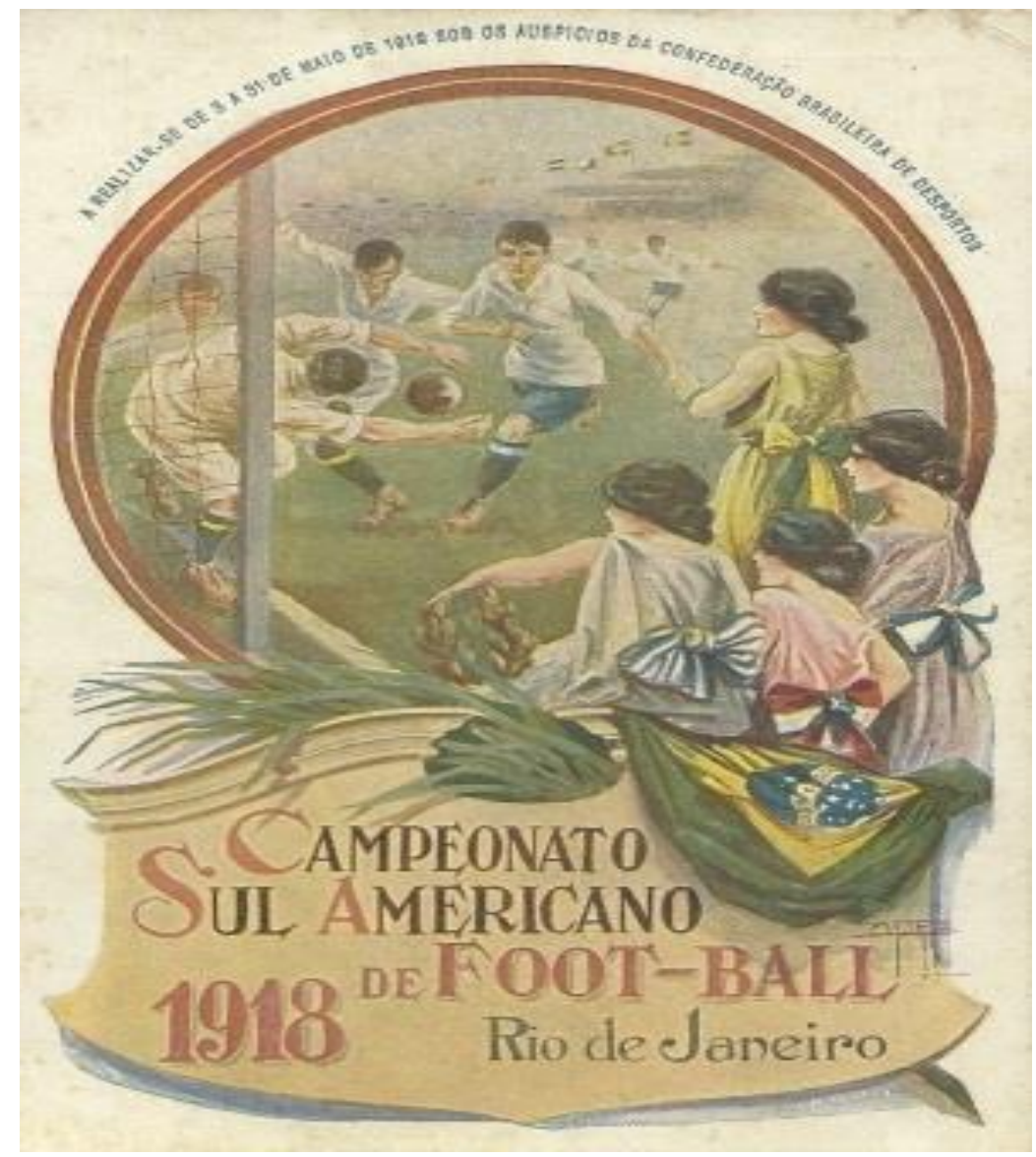

Os efeitos da "Gripe Espanhola" decerto promoveram muitos desdobramentos sobre o futebol. Na percepção de algumas pessoas, a pandemia provocara um arrefecimento na "mania" do esporte bretão. O jornal $O$ Pharol, da cidade mineira de Juiz de Fora, publica em sua edição de 4 de fevereiro de 1919, uma nota intitulada Educação Physica, em que aponta:

\footnotetext{
${ }^{9}$ http://ribeiraopretoculturaljaf.blogspot.com/2018/08/cartao-postal-alusivo-realizacao-do.html.
} 
O football chegou a ser uma mania. Os clubs desse genero de sport proliferavam e proliferam ainda por todo o Brazil, desde a capital da União até as menores cidades e povoados do interior. Não há criança que não entenda a technicologia (sic)dos footballers e que não dê um pontapé numa bola, numa caixa de phosphorovasia, numa laranja, num embrulho de papel, dentro de casa, na rua, em toda a parte. Pois essa febre está diminuindo e ameaça desapparecer, para tranquilidade das vidraças, dos transeuntes e das mamães e com prejuízo para a educação physica da mocidade brazileira. [...] Lamentamos também o declínio do football, útil ao desenvolvimento physico de nossa mocidade. A causa de haver diminuído o enthusiasmo pelo football foi a epidemia da grippe. Depois dessa pandemia as secções sportivas quase desappareceram dos jornaes (GUIMAR ̃̃ES, 1917, p. 1).

No entanto, a visão pessimista do jornalista juiz-forano não parece ser a predominante. No início de 1919 os principais campeonatos das grandes cidades brasileiras retornam com uma aparente normalidade, sem evidências de uma alteração profunda nos hábitos do jogo e do torcer. O jornal carioca A Rua, na edição de 07 de maio de 1919, em alusão à proximidade do Campeonato Sul-Americano e a recente passagem da febre espanhola, chega a afirmar que "antes do campeonato, o football aqui já era uma doença: agora é uma grande epidemia, a coqueluche da cidade, de que ninguém escapa".

De fato, a realização do Sul-Americano de 1919 marca o retorno triunfante do futebol brasileiro, notadamente pela exitosa campanha do selecionado brasileiro. Naquele instante, a pandemia não parecia ser uma lembrança com força suficiente para frear o entusiasmo esportivo provocado pelo futebol. O estádio lotado de pessoas, contrariando as recomendações de distanciamento social, é um reflexo deste panorama, contrastando com as precauções adotadas em outros países, como ilustrado nas figuras 03 e 04 abaixo: 


\section{Figura 03: Torcida Brasileira no Final do Campeonato Sul-Americano, 29.05.1919. ${ }^{10}$}

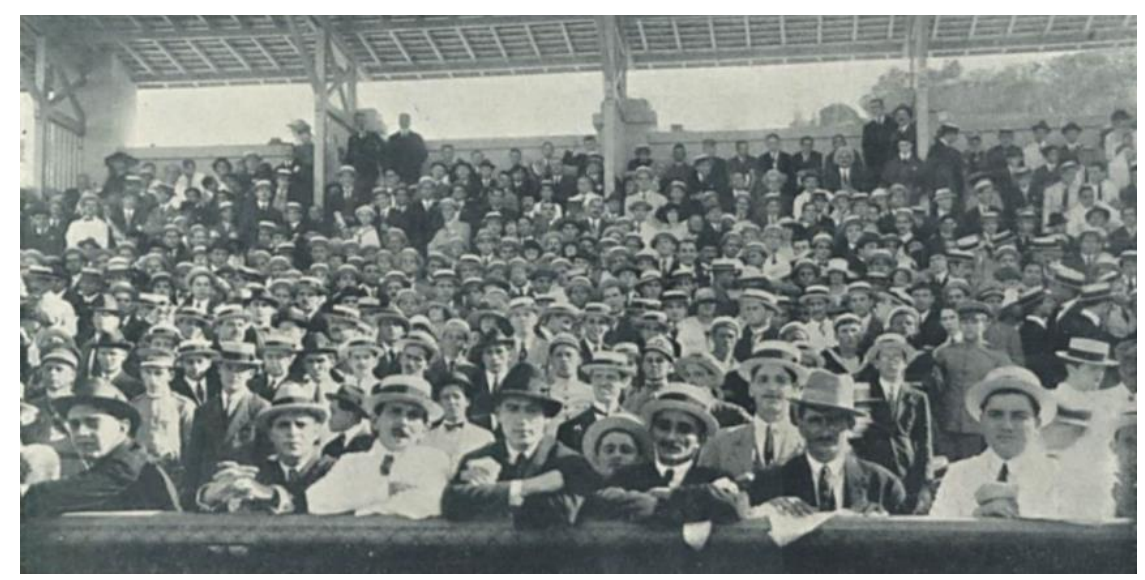

Figura 04: Torcida no Campeonato Universitário em 1918, estádio do Georgia Tech, USA. ${ }^{11}$

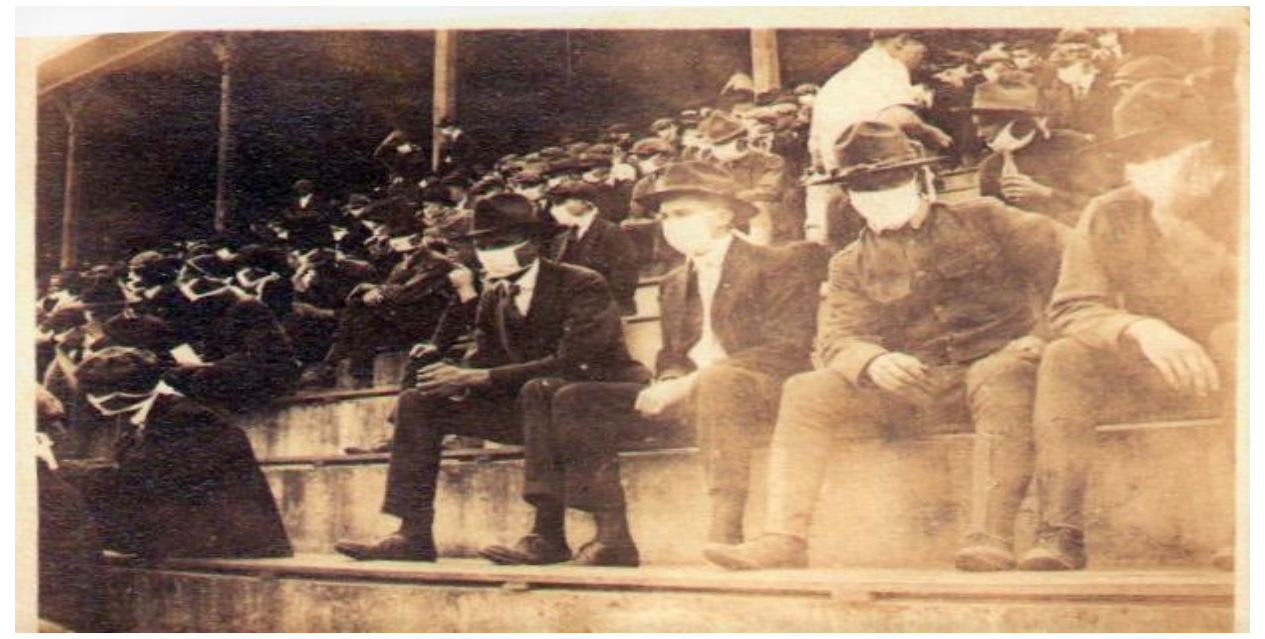

Em Belo Horizonte, a pandemia de 1918 também atinge com força a jovem capital.

Com uma população de 50 mil habitantes naquele ano, estima-se que dois mil moradores tenham sido infectados (o que equivale a $4 \%$ do total de habitantes). Todo este cenário atingiria em cheio o Campeonato Mineiro, que teve a sua disputa paralisada por 83 dias, no período de 29 de setembro (quando registrou a última partida antes da paralisação,

\footnotetext{
${ }^{10} \mathrm{http}: / /$ trivela.com.br/o-titulo-que-transformou-a-historia-do-futebol-no-brasil-ha-100-anos-a-selecaoconquistava-o-sul-americano-de-1919/.

${ }^{11} \mathrm{http} / / /$ twitter.com/MrCFB/status/1257835680157351938?ref_src=twsrc\%5Etfw\%7Ctwcamp\%5Etweete mbed\%7Ctwterm\%5E1257835680157351938\%7Ctwgr\%5E\&ref_url=https\%3A\%2F\%2Fwww.flunomen o.com\%2F2020\%2F05\%2Ffake-nao-foi-no-fluminense-foto-de.html.
} 
entre Atlético x Luzitano) a 22 de dezembro (data que marcaria o retorno do campeonato, com o jogo entre América x Sete de Setembro).

\title{
O processo de Modernização do Futebol nos Anos 1990 e suas Consequências no
}

\section{Modelo de Gerenciamento do/no Torcer}

Após a Gripe Espanhola de 1918, o futebol e o torcer continuam se desenvolvendo como um fenômeno social cada vez mais arraigado na cultura citadina/urbana, arrebatando uma multidão de pessoas atreladas ao seu entorno, notadamente na constituição ampla, densa e consistente das torcidas/torcedores.

A profissionalização do futebol no país, processo que nos grandes centros urbanos se efetivou em 1933, acelera o esporte na lógica da sua primeira onda de modernização. A pesquisadora Sarah Soutto Mayor advoga a ideia de que, a partir das décadas de 1930 e 1940, impulsionado pelo ethos do profissionalismo,

\begin{abstract}
O particularismo dos momentos finais do século XIX e dos primeiros anos do século XX cedeu espaço para a valorização de uma nova característica do futebol: a sua espetacularização e a sua massificação. $\mathrm{O}$ aumento do público consumidor significava para muitos clubes do Brasil, já em meados da década de 1910, uma possibilidade interessante de enriquecimento e de aquisição de prestígio social. [...] Mesmo que este fenômeno já tenha se iniciado em momento anterior, pode-se dizer que a adoção às claras do profissionalismo o potencializou, na medida em que concentrou a força do empreendimento futebolístico, de forma evidente, nas possibilidades mercadológicas (SOUTTO MAYOR, 2017, p. 121).
\end{abstract}

Neste sentido, com o viés espetacularizado e com a presença cada vez mais determinante do mercado, os modos de torcer também são ressignificados a partir deste novo ordenamento. No final dos anos 1940 surgem as primeiras torcidas uniformizadas (TUF's), e na década de 1960 as chamadas torcidas organizadas (TO's) se constituem no cenário do futebol brasileiro. A formação destes grupos certamente é estimulada pelo conjunto de forças atuante na dinâmica organizacional do esporte, pautado em larga escala por entidades representativas mais operantes, um gerenciamento mais ativo e 
orgânico dos clubes e pelo poder político e econômico cada vez mais prestigioso e dominante. Todo este contexto pode ser assim interpretado, nas palavras de Luiz Henrique de Toledo:

\begin{abstract}
A cidade cresceu, atingindo os contornos que hoje são conhecidos, agrupando gostos e preferências clubísticos. Com isso, novas formas de entretenimento e lazer foram gestadas a partir da prática e paixão pelo futebol. E desta prática novos atores emergiram: jogadores profissionais, dirigentes e políticos de times, imprensa especializada, bem como a popularização de torcedores que se notabilizaram pela excessiva devoção e paixão aos times (os torcedores símbolos) e, mais recentemente, as Torcidas Organizadas, que surgiram em um momento de grandes mudanças pelas quais passou a relação futebol e sociedade (TOLEDO, 1996, p. 20).
\end{abstract}

De fato, entre as décadas de 1970/1990, as Torcidas Organizadas, com suas dinâmicas bastante próprias e singulares, tornam-se preponderantes no que tange aos modos de torcer nos estádios (numa época em que a transmissão televisiva ainda era bastante tímida). É a partir delas que a codificação de pertencimento e modelo torcedor nos estádios brasileiros se forja. No entanto, após os anos 90, e principalmente no século XXI, esse modelo torcida/torcedor será profundamente impactado, necessitando inclusive se constituir em outro patamar organizativo para não falir em sua existência.

Para melhor compreender esse panorama, tomamos aqui as análises produzidas por Irlan Santos e Ronaldo Helal, que pautaram quatro grandes marcos históricos na estruturação constitutiva do futebol em um esporte substancialmente alinhado ao campo mercadológico e hiperespetacularizado.

O primeiro marco se dá no Pós-Guerra, e mais acentuadamente a partir dos anos 1960, na formação de uma sociedade do consumo, onde se nota uma "novaforma de condução do futebol enquanto negócio por uma geração de dirigentes atrelados ao mundo corporativo, muito influenciado por uma americanização da cultura global" (SANTOS; HELAL, 2016, p. 60). O segundo momento é marcado pela gestão de João Havelange à frente da FIFA (1974), que potencializa a visão mercantil e de negócios no futebol. A 
tragédia de Hillsborough, em 1989, na Inglaterra se constitui como terceiro marco deste processo. O lamentável episódio, que gerou 96 mortos e centenas de feridos devido à uma superlotação do estádio, acabou provocando uma reação do governo neoliberal inglês, que resultou na produção do conhecido Relatório Taylor, indicando uma profunda reformulação dos estádios, o que acabou legitimando o discurso de um novo modelo de gerenciamento do espaço e do público, centrado na alta taxação dos ingressos e promovendo uma elitização do espetáculo futebolístico. Por fim, um quarto momento, marcado pela adoção de um novo padrão de estádios, transformados em arenas multiusos e impostos como condição para a realização de eventos organizados sob a tutela das entidades FIFA e UEFA (SANTOS E HELAL, 2016).

A recente experiência de sediar uma Copa do Mundo fez com que o Brasil adotasse sistematicamente esse modelo de gerenciamento do futebol, e consequentemente do torcer. A lógica do futebol espetáculo e mercadológico se materializou na construção das arenas, mas acontece sub-repticiamente em ações como: maior investimento dos clubes em uma gestão empresarial; sócio-torcedores como política estruturante (o que abala fortemente o sentido das torcidas organizadas); justificativa para ingressos caros (já que o serviço ofertado será de maior qualidade); aposta em mídias sociais e ferramentas virtuais de promoção do clube; retorno financeiro a partir da exploração da marca do clube em produtos oficiais (as lojas oficias físicas e virtuais cresceram enormemente); incremento do retorno televiso através dos programas de pay-per-views. 


\section{Consequências e Possibilidades para o Torcer a Partir da Pandemia do Novo}

\section{Coronavirus}

Em meio à pandemia da Covid-19 12 é um tanto difícil diagnosticar como será o torcer no pós-pandemia, uma vez que traz mudanças avassaladoras no cotidiano das famílias. Tudo o que for hipotetizado, serão conjecturas baseadas nas análises dos fatos do passado e do presente.

Sendo assim, um movimento observado durante esse período e que impacta a experiência do/no torcer é o aumento do acesso à tecnologia streaming. Existente desde a década de 1990, o streaming ganhou maior visibilidade com a chegada da internet de banda larga que possibilitou uma maior velocidade no carregando das informações de imagem e $\operatorname{som}^{13}$. A popularização do streaming traz um número incalculável de possibilidades, entre elas, acompanhar um evento ao vivo pela tela do computador, tablet ou smartphone, sem precisar de um canal de televisão.

Essa tecnologia, bem como a popularização da internet, possibilita aos clubes investir na produção de conteúdo a seu respeito, não ficando restritos às mídias hegemônicas. Isso gera no torcedor uma sensação de maior proximidade ao clube, uma vez que dirigentes, jogadores, treinamentos e todas as etapas do jogo (concentração, embarque, chegada ao estádio, partida, pós-partida) se tornam produtos e o torcedor pode acessar o conteúdo de onde estiverem incorporando principalmente àqueles que não moram na mesma cidade que o clube do coração.

Vale ressaltar que no cenário mundial vários clubes já possuem os seus canais de televisão e, inclusive, compram o direito de transmissão de seus jogos acirrando a disputa

\footnotetext{
12 No dia 10 de agosto de 2020, o Brasil registou 101.857 mortes por Covid-19 e 3.056 .312 brasileiros infectados. Maiores informações: http:/g1.globo.com/bemestar/coronavirus/noticia/2020/08/10/casos-emortes-por-coronavirus-no-brasil-em-10-de-agosto-segundo-consorcio-de-veiculos-de-imprensa.ghtml.

${ }^{13} \mathrm{http}: / / \mathrm{www}$. techtudo.com.br/artigos/noticia/2013/05/conheca-o-streaming-tecnologia-que-sepopularizou-na-web.html.
} 
com as emissoras hegemônicas. No Brasil, muitos clubes já possuíam seus canais, em sua maioria, o objetivo era trazer ao torcedor um conteúdo exclusivo de treinamentos, entrevistas e curiosidades sobre o cotidiano do clube. A transmissão por streaming entrou na agenda em 2017 quando Athletico Paranaense e Coritiba ameaçaram transmitir a partida final do campeonato paranaense pelo youtube, após os clubes não entrarem em acordo com a Rede Globo ${ }^{14}$.

De lá para cá a ideia foi amadurecendo e serviu como base para a publicação da Medida Provisória nº. 984, de 18 de junho de 2020 que trata dos direitos de transmissão e duração do contrato de trabalho de atletas durante a pandemia da covid-19. Em suma, de acordo com a MP, "pertencem ao clube (entidade de prática desportiva) mandante do jogo os direitos de negociar, autorizar ou proibir a captação, a fixação, a emissão, a transmissão, a retransmissão ou a reprodução de imagens, por qualquer meio ou processo, do espetáculo desportivo" (BRASIL, 2020).

Dessa forma, alterando substancialmente a Lei Pelé, a MP determina que o direito de arena passa a pertencer, exclusivamente, ao time mandante. Este terá autonomia para negociar a transmissão de seus jogos e o direito de imagem, seja por meio de uma emissora de televisão ou streaming. Uma das premissas é que haverá uma maior democratização do futebol, uma vez que os clubes não ficarão presos a uma rede de televisão específica ${ }^{15}$ e nem dependerão do ciente do adversário para estipular valores.

Se há a premissa de uma democratização e o aumento da autonomia dos clubes, podemos contra-argumentar que nem todos os clubes poderão investir na manutenção de uma equipe para a produção de conteúdo, tornando-se algo custoso e nem todos terão um quantitativo suficiente de torcedores para sustentar tal empreitada. Ademais, sem ter uma

\footnotetext{
${ }^{14} \mathrm{http} / /$ parananews.net.br/coritiba-e-atletico-pr-farao-transmissao-inedita-de-classico-pelo-youtube/. http://exame.com/negocios/transmissao-no-youtube-cancela-classico-de-futebol-no-pr/.

${ }^{15} \mathrm{http}$ //www.uol.com.br/esporte/futebol/ultimas-noticias/2020/06/19/bolsonaro-diz-estar-emocratizandoo-futebol-com-mp-dos-direitos-de-tv.htm.
} 
unidade, cada clube disputará por si só o tão movimentado mercado futebolístico, competindo com o mercado interno e externo na captação do torcedor. Isto é, cada clube deverá oferecer um produto capaz de fidelizar o seu torcedor de modo que ele não faça a aderência a outro campeonato/programa. Veremos clubes locais sendo engolidos por clubes globais. Com isso, o fosso que separa os clubes brasileiros pode aumentar e pode haver boicote na transmissão para as equipes adversárias.

Sendo assim, em longo prazo, essa nova forma de assistir às partidas futebolísticas pode influenciar sobremaneira na educação para o torcer, tendo em vista que o torcedor poderá acessar a partida de qualquer lugar em tempo real, interagir com ela, deixando seus comentários e postagens, entre outros serviços que a tecnologia será capaz de oferecer para que a experiência seja única para cada sujeito, objetivando, ainda mais, a customização do torcedor.

Em outro plano, uma das consequências do torcer a partir da pandemia do Novo Coronavírus diz respeito a assistência no estádio. Sabemos que o estádio é o templo sagrado do torcedor e que a cultura do estádio foi modificada ao longo da história. No Brasil, como visto, um marco na alteração da cultura dos estádios foram as reformulações sofridas para sediar a Copa do Mundo, em 2014. No pós-Copa estava em curso a disputa discursiva e de ethos sobre o torcer e o proceder nesse novo espaço. Nesse contexto, os estádios brasileiros, sinônimos de democracia e inclusão social, se viram transformados em um lugar homogeneizado e segregador. Os torcedores foram transformados em consumidores e o torcer em mercadoria. Algumas tradições, rituais e manifestações foram enterradas nos escombros da reforma. Nasceu uma nova forma de assistência: cadeiras em toda a arquibancada, lugar numerado e um torcedor sentado, comedido em suas manifestações e preocupado com sua postagem nas redes sociais em contraste com a festa das arquibancadas de outrora. 
E no pós Covid-19, como será a volta do torcedor ao estádio? As pressões econômicas e políticas anteciparão essa volta para durante a pandemia? Os estádios ficarão lotados? $\mathrm{Na}$ atualidade, em um momento de isolamento social no qual as aglomerações são proibidas, o outro visto como uma ameaça à saúde, como se dará a experiência do torcer? Haverá a obrigatoriedade do uso de máscaras?Será que cada torcedor ficará mais confinado em seu acento? As emoções coletivas presentes em um estádio, manifestadas em lances de gol ou adversos, como ocorrerão? Como será que esse torcedor, educado à nova conectividade e com conteúdos cada vez mais específicos ao seu perfil se comportará em um ambiente tão diverso, amplo e de riqueza sensorial como o estádio de futebol? Estarão todos presentes assistindo à partida pela tela de seus smartphones em busca da exclusividade? Essas são indagações que só o tempo responderá.

\section{Considerações Finais}

Diante do exposto, verificamos que não houve um impacto muito grande da Gripe Espanhola no futebol, principalmente pelo fato desse campo estar em formação. No momento atual, o pertencimento clubístico já está sedimentado e o futebol tornou-se um produto rentável, com isso a pandemia do Covid-19 traz transformações imensuráveis na forma do torcer. Além disso, a questão tecnológica e a hiperespetacularização parecem ser elementos que acentuam essas mudanças.

No mais, não podemos deixar de mencionar que a experiência do torcer no estádio é catalizadora no processo de formação e fidelização do torcedor. É ela um elo primordial na relação torcedor-clube. É no estádio, por meio da convivência, da pluralidade de acontecimentos que ocorre com o sujeito e com os outros a sua volta, agregada ao futebol e ao pertencimento clubístico que são formadas as tramas e os enredos para as narrativas 
do/no estádio e que constituem a identidade do/a torcedor/a. Abrir mão desse espaço é uma forma de esvaziar essa relação de cumplicidade estabelecida entre o torcedor e o clube, uma vez que, sem identidade clubística, o sujeito irá procurar o jogo que lhe dá maior prazer ou status.

\section{REFERÊNCIAS}

BRASIL. Medida Provisória no. 984. Jun. 2020 Disponível em http://www.congressonacional.leg.br/materias/medidas-provisorias/-/mpv/142594. Acesso em: 10 ago. 2020.

CBF - CONFEDERAÇÃO BRASILEIRA DE FUTEBOL. Guia Médico de Sugestões Protetivas Para o Retorno às Atividades do Futebol Brasileiro. 2020. Disponível em: http://conteudo.cbf.com.br/cdn/202006/20200610151650_484.pdf. Acesso em: 10 ago. 2020 .

GUIMARÃES, H. Educação Physica. O Pharol. Juiz de Fora, 04 fev. 1919, p. 1.

MINAS Geraes. Belo Horizonte, 26 jul. 1914. Seção Festas e diversões - Notas Sportivas, p. 11.

MINAS Geraes. Belo Horizonte, 24 set. 1915. Seção Festas e diversões (Campeonato de Foot-Ball), p.6.

SANTOS, I. S.; HELAL, R. G. Do espectador ao militante: a torcida de futebol e a luta pelo direito ao estádio e ao clube. Tríade: comunicação, cultura e mídia. Sorocaba, SP, v. 4, n. 7, p. 53-69, jun. 2016.

SOUTTO MAYOR, S. T. O futebol na cidade de Belo Horizonte: amadorismo e profissionalismo nas décadas de 1930 e 1940. 2017. 358 f. Tese (Doutorado) Universidade Federal de Minas Gerais, Escola de Educação Física, Fisioterapia e Terapia Ocupacional, Belo Horizonte, 2017.

TOLEDO, L. H. Torcidas Organizadas de Futebol. Campinas: Autores Associados, 1996. 176p.

WISNIK, J. M. Veneno remédio: o futebol e o Brasil. São Paulo: Companhia das Letras, 2008. 430p.

\section{Endereço dos(as) Autores(as):}

Georgino Jorge de Souza Neto

Campus Universitário Prof. Darcy Ribeiro

Av. Prof. Rui Braga, s/n - Vila Mauriceia 
Montes Claros - MG - 39.401-089

Endereço Eletrônico: netogeorgino@gmail.com

Priscila Augusta Ferreira Campos

Escola de Educação Física da UFOP

Rua Dois, 110 - Bauxita

Ouro Preto - MG - 35.400-000

Endereço Eletrônico: priafcbr@yahoo.com.br

Silvio Ricardo da Silva

GEFuT/EEFFTO/UFMG

Av. Pres. Antônio Carlos 6627 - Pampulha

Belo Horizonte -MG -31.270-901

Endereço Eletrônico: prof.srs@gmail.com 